\title{
Decomposition of lipid hydroperoxides enhances the uptake of low density lipoprotein by macrophages ${ }^{\star}$
}

\author{
Alexander V. Babiy and Janusz M. Gebicki ${ }^{*}$ \\ School of Biological Sciences, Macquarie University, Sydney, Australia
}

Received: 20 January, 1999

Key words: free radicals, low density lipoprotein, lipid, hydroperoxide, macrophage, oxidized LDL, aggregated LDL

\begin{abstract}
This study examined the roles of low-density lipoprotein (LDL) lipid oxidation and peroxide breakdown in its conversion to a form rapidly taken up by mouse peritoneal macrophages. Oxidation of the LDL without decomposition of the hydroperoxide groups was performed by exposure to gamma radiation in air-saturated solutions. Virtually complete decomposition of the hydroperoxides was achieved by treatment of the irradiated $\mathrm{LDL}$ with $\mathrm{Cu}^{2+}$ under strictly anaerobic conditions. No uncontrolled LDL uptake by macrophages occurred when the lipoprotein contained less than $\mathbf{1 5 0}$ hydroperoxide groups per particle. More extensively oxidized LDL was taken up and degraded by mouse macrophages significantly faster than the native lipoprotein. The uptake was greatly enhanced by treatment of the oxidized LDL with $\mathrm{Cu}^{2+}$. A significant proportion of the LDL containing intact or copper-decomposed LDL hydroperoxide groups accumulated within the macrophages without further degradation. Treatment of the radiation-oxidized $\mathrm{LDL}$ with $\mathrm{Cu}^{2+}$ was accompanied by aggregation of the particles. Competition studies showed that the oxidized LDL was taken up by macrophages via both the LDL and the scavenger receptors, whereas the copper-treated lipoprotein entered the cells only by the scavenger pathway. Phagocytosis also played an important role in the metabolism of all forms of the extensively modified LDL. Our results suggest that minimally-oxidized LDL is not recognized by the macrophage scavenger receptors unless the lipid hydroperoxide groups are decomposed to products able to derivatize the apo B protein.
\end{abstract}

\footnotetext{
* This project was supported by the National Heart Foundation and a Macquarie University Research Grant.

${ }^{\star}$ Author for correspondence: Dr. J.M. Gebicki, School of Biological Sciences, Macquarie University, Sydney 2109, Australia; tel.: (612) 9850 8252, fax.: (612) 805 8245, e-mail: jgebicki@rna.bio.mq.edu.au Abbreviations: LDL, low-density lipoprotein; LDS, lipoprotein deficient serum; ox-LDL, oxidized LDL; ox-Cu-LDL, oxidized LDL treated with $\mathrm{Cu}^{2+}$; TBARS, thiobarbituric acid reactive substances; BSA, bovine serum albumin.
} 
Modification of human LDL by certain reactive compounds [1-3], oxidation [4-5], or aggregation $[6,7]$ has been convincingly shown to convert native LDL into forms, capable of entering macrophages by their scavenger receptors and inducing massive accumulation of cholesterol. In vivo, the generation of most of the modified forms of LDL is believed to depend on oxidation of its unsaturated lipids, followed by the modification of apo B lysine residues by aldehydes generated during subsequent peroxide decomposition [8, 9]. The major source of the oxidants are monocytemacrophages and smooth muscle and endothelial cells in the arterial walls releasing a range of reactive molecules and free radicals which initiate LDL lipid oxidation directly or with the participation of transition metals [10].

The process of recognition of modified LDL by the cellular receptor depends on the alteration of the protein component of the particle, and there is evidence that oxidation of the apo $\mathrm{B}$ can occur in the absence of lipid oxidation and is sufficient to generate LDL recognized by the macrophage scavenger receptors [11]. In practice, it is not usually possible to evaluate the relative contributions of the oxidation and peroxide decomposition to the formation of atherogenic LDL; LDL oxidation is simulated in vitro most commonly by incubation under aerobic conditions with low concentrations of $\mathrm{Cu}^{2+}$ or with cells in presence of metal ions, when both the formation and breakdown of lipid peroxides occur [12]. However, such differential evaluation may be important not only for the understanding of the mechanism of LDL modification, but also for potential selective therapeutic interference with either oxidation or peroxide breakdown.

The use of ionizing radiation to oxidize the LDL offers the opportunity to study lipid oxidation in virtual absence of decomposition. This approach showed that hydroperoxides were generated in irradiated LDL most readily by the $\mathrm{HO}^{\circ}$ free radical in the presence of $\mathrm{O}_{2}$, followed by $\mathrm{OH}_{2}^{*}$, with superoxide radical giving only sufficient oxidation to stimulate further peroxide formation by $\mathrm{Cu}^{2+}$ [13]. However, exposure of the LDL to radiationgenerated radicals did not result in its conversion to the form taken up by the macrophage scavenger receptors. The authors suggested that formation of this modified LDL may require catalytic decomposition of the LDL lipid peroxides by redox-active metals, but they did not study this proposition.

The aim of the present study was to examine separately the effects of LDL lipid oxidation and hydroperoxide breakdown on its uptake by macrophages. Oxidation of LDL without significant peroxide decomposition was achieved by exposing air-saturated aqueous solutions of the lipoprotein to hydroxyl radicals generated by gamma radiation. Decom. position of the hydroperoxides was achieved by treatment with $\mathrm{Cu}^{2+}$ in absence of oxygen, when no new peroxide groups could be generated. The results show that peroxide decomposition does play an important role in formation of atherogenic forms of the LDL.

\section{MATERIALS AND METHODS}

All chemicals were of analytical grade and purchased from BDH Chemicals (Sydney, Australia), Sigma (St. Louis, MO, U.S.A.), AJAX Chemicals (Sydney, Australia), or Merck (Darmstadt, Germany). Cell culture medium, fetal calf serum, penicillin, streptomycin and heparin were obtained from Gibco Laboratories (Grand Island, NY, U.S.A.). Cytochalasin B was purchased from Sigma (St. Louis, MO, U.S.A.). $\mathrm{Na}^{125}$ I was obtained from Amersham (U.K.).

Lipoprotein preparation. Whole blood was obtained from healthy subjects by venipuncture and collected in tubes with EDTA $(1 \mathrm{mg} / \mathrm{ml})$ as anticoagulant. LDL was isolated from the freshly drawn plasma using a Spinco-Beckman ultracentrifuge equipped with SW-41 rotor, according to the method of Redgrave et al. [14]. After separation, the 
lipoprotein samples were dialyzed for $24 \mathrm{~h}$ at $4^{\circ} \mathrm{C}$ against three changes of 200 volumes of $0.15 \mathrm{M} \mathrm{NaCl}$ buffered with $2 \mathrm{mM}$ phosphate pH 7.4, deoxygenated by continuous bubbling with argon. EDTA, $1 \mathrm{mg} / \mathrm{ml}$, was present throughout the isolation procedure except for the last change of the dialysis buffer. After dialysis, the lipoprotein samples were sterilized by filtration through a $0.45 \mu \mathrm{m}$ membrane and stored until use for not longer than one week. Acetylation of the LDL was performed by sequential addition of acetic anhydride [1]. The LDL was labeled with ${ }^{125}$ I to a specific activity 200-300 c.p.m./ng protein by the iodine monochloride procedure [15].

LDL oxidation and peroxide decomposition. The lipoprotein solution containing 1 $\mathrm{mg} / \mathrm{ml}$ protein in buffered $0.15 \mathrm{M} \mathrm{NaCl}$ was exposed to $\gamma$ radiation from a ${ }^{60} \mathrm{Co}$ source at a dose rate of $50 \mathrm{~Gy} / \mathrm{min}$ at room temperature ( $1 \mathrm{~Gy}=1 \mathrm{~J}$ of energy absorbed per $\mathrm{kg}$ ). Immediately following irradiation the LDL samples were incubated with catalase $(0.02 \mathrm{mg}$ protein $/ \mathrm{ml}$ ) for $10 \mathrm{~min}$ to remove radiolytically generated $\mathrm{H}_{2} \mathrm{O}_{2}$. Decomposition of the LDL hydroperoxides was performed as follows. The irradiated LDL $(0.91 \mathrm{mg} / \mathrm{ml})$ solution was flashed with argon for 3-5 min. $\mathrm{CuCl}_{2}$ was then added to a final concentration of 20 $\mu \mathrm{M}$, the mixture immediately flashed with argon for $20 \mathrm{~min}$ and then incubated under argon atmosphere for $10-19 \mathrm{~h}$. The incubation was stopped by the addition of EDTA, to 100 $\mu \mathrm{M}$ final concentration and cooling on ice. When required, prior to the addition of the oxidized LDL to macrophages, the samples were concentrated by ultrafiltration in Centricon-30 microconcentrator (Amicon, Danvers, MA, U.S.A.) to $2-3 \mathrm{mg} / \mathrm{ml}$ and sterilized by filtration through $0.45 \mu \mathrm{m}$ filter. Measurement of the hydroperoxides was performed by a modification of the tri-iodide assay [16], adapted for aerobic conditions as described elsewhere [17]. All measurements were made in duplicates which differed by less than $5 \%$.
Uptake and accumulation of LDL cholesterol by macrophages. Mouse resident macrophages were isolated by peritoneal lavage, and $1.5 \times 10^{6}$ cells were put into each well of 24-well dishes in Dulbecco's modified Eagle medium containing 100 units/ml penicillin, 100 units $/ \mathrm{ml}$ streptomycin, and 10 units/ml heparin. After $2 \mathrm{~h}$ incubation, nonadherent cells were removed by washing the wells four times with the medium without heparin. All incubations of the LDL with macrophages were carried out in $0.5 \mathrm{ml}$ of the medium which contained the antibiotics and either $5 \%$ of LDS and $100 \mu \mathrm{g} / \mathrm{ml} \mathrm{LDL} \mathrm{(in} \mathrm{cho-}$ lesterol accumulation experiments), or $10 \%$ fetal calf serum and $20 \mu \mathrm{g} / \mathrm{ml}$ of ${ }^{125} \mathrm{I}$-labeled LDL (for the determination of LDL uptake). At the end of incubations $(15 \mathrm{~h}$ in cholesterol accumulation and $20 \mathrm{~h}$ in experiments with ${ }^{125} \mathrm{I}-\mathrm{LDL}$ ) the medium was removed and the cells were washed 3 times with phosphatebuffered saline. Free and esterified cholesterol was extracted from the cells by isopropanol and measured by enzymatic assay [18]. No detectable amounts of cholesterol were found in cell-free parallel control incubations. In experiments with ${ }^{125} \mathrm{I}-\mathrm{LDL}, 0.4 \mathrm{ml}$ of the culture medium was removed, mixed with $0.08 \mathrm{ml}$ of BSA $(30 \mathrm{mg} / \mathrm{ml})$ and $0.8 \mathrm{ml}$ of icecold $3 \mathrm{M}$ trichloroacetic acid and centrifuged at $1500 \mathrm{~g}$ for $10 \mathrm{~min}$ at $4^{\circ} . \mathrm{AgNO}_{3}(0.2 \mathrm{ml}, 0.7$ M) was then added to the samples and the centrifugation step was repeated. A $0.5 \mathrm{ml}$ sample of the iodide-free acid-soluble supernatant was removed and its radioactivity determined. The washed macrophages were lysed in $0.5 \mathrm{ml}$ of $0.2 \mathrm{M} \mathrm{NaOH}$ for at least 20 $\mathrm{min}$ and assayed for protein and radioactivity content.

Other methods. For the determination of thiobarbituric acid reactive substances (TBARS), $100 \mu \mathrm{l}$ of the LDL sample was mixed with $300 \mu \mathrm{l}$ of $20 \%$ trichloroacetic acid and $300 \mu \mathrm{l}$ of $0.67 \%$ thiobarbituric acid. After incubation at $80^{\circ}$ for $1 \mathrm{~h}$, the samples were centrifuged and the absorbance of the super- 
natant read at $532 \mathrm{~nm}$. Freshly prepared malonaldehyde tetramethyl acetal solution was used as a standard and the results were expressed in units of malondialdehyde equivalents. Agarose gel electrophoresis was carried out in a Titan Gel Chamber, using Titan Gel Lipoprotein Kit (Helena Laboratories, Australia) according to the manufacturer's instruction manual. Protein was determined by the Lowry method [19] with BSA as standard. Electron microscopy of LDL samples, negatively stained by phosphotungstic acid, was performed as described by Forte and Nordhausen [20].

\section{RESULTS}

In agreement with numerous previous studies, we confirmed that aerobic incubation of human LDL with $20 \mu \mathrm{M} \mathrm{Cu}^{2+}$ resulted in its oxidation, with formation of hydroperoxides, TBARS and an increase in anodic electrophoretic mobility (not shown). The yields of hydroperoxides and TBARS reached a maximum after approx. $15 \mathrm{~h}$ of incubation and then gradually decreased. In the course of oxidation, the LDL progressively acquired the ability to induce cholesterol accumulation in mouse macrophages. Irradiation of LDL with gamma rays also led to its oxidation, assayed by the reaction with iodide [16], and increase in TBARS content, as reported earlier [13]. We found considerable variability in the oxidizability of LDL samples isolated from different individuals, but in each case the TBARS values were proportional to the length of irradiation and to the amount of authentic peroxide generated. However, the ratios of TBARS to hydroperoxides in each irradiated sample were 10-20 times lower than the corresponding values for $\mathrm{LDL}$ oxidized by $\mathrm{Cu}^{2+}$, suggesting that the metal induced significant peroxide breakdown as well as formation.

The effect of LDL hydroperoxide breakdown on LDL modification was studied by incubating $\mathrm{LDL}$ oxidized by irradiation with $\mathrm{Cu}^{2+}$ un- der anaerobic conditions. This prevented the formation of new peroxides. The results (Fig. 1) show that the metal greatly accelerated the loss of the hydroperoxide groups when compared to copper-free controls. The decomposition was retarded by low temperatures and EDTA.

The relationship between the amount of radiation energy absorbed and the formation of LDL hydroperoxides and TBARS before and after anaerobic $\mathrm{Cu}^{2+}$ treatment are shown in Fig. 2A. Since the radiation dose was directly proportional to the length of the irradiation, these experiments provided kinetic data. The results do not allow estimation of the usual lag period in hydroperoxide formation [17] because relatively large radiation doses were employed. High TBARS readings were obtained in the presence of both high and low peroxide levels, showing that TBARS values are not a valid assay of hydroperoxide levels when the conditions favor peroxide breakdown. The results also show the very high efficiency of $\mathrm{Cu}^{2+}$ as catalyst of hydroperoxide breakdown. Although significant amounts of hydroperoxides formed in the LDL immedi-

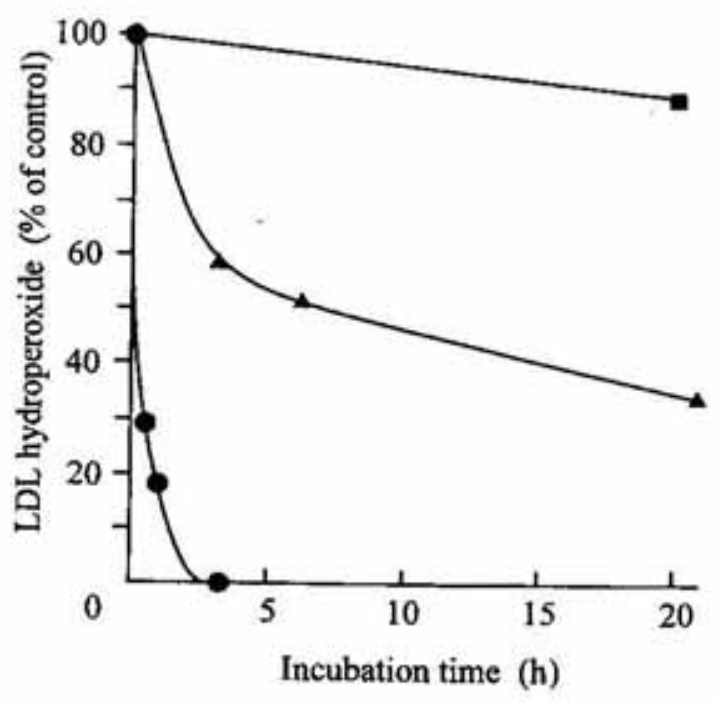

Figure 1. Spontaneous and catalyzed anaerobic decomposition of LDL hydroperoxides.

The initial hydroperoxide concentration generated by gamma radiation was $0.19 \mu \mathrm{mol} / \mathrm{mg}$ protein. The lines show: $\mathbf{\square}, 0.1 \mathrm{mM}$ EDTA, $4^{\circ} \mathrm{C} ; \boldsymbol{\Delta}, 37^{\circ} \mathrm{C} ; \boldsymbol{\bullet}, 20 \mu \mathrm{M}$ $\mathrm{Cu}^{2+}, 37^{\circ} \mathrm{C}$. 

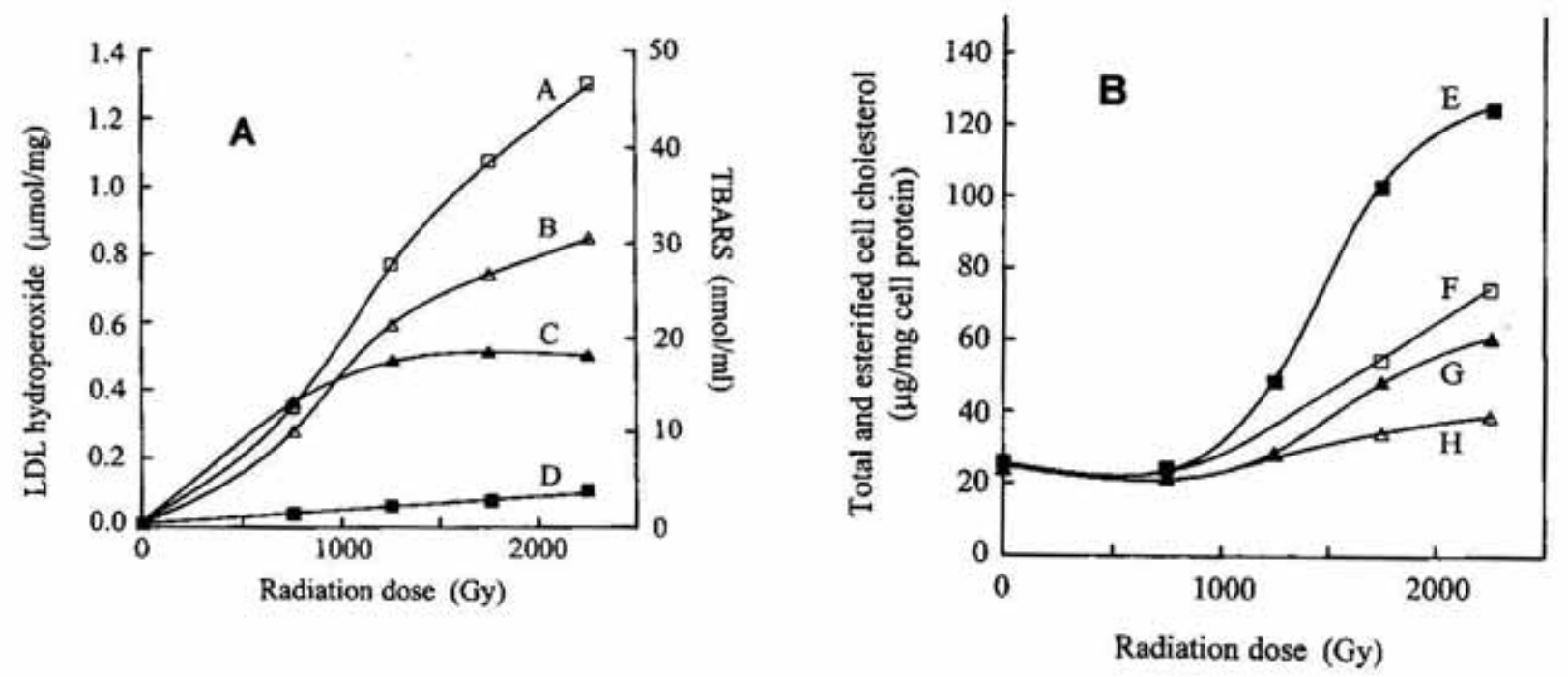

Figure 2. The effect of radiation on the formation and uptake of ox-LDL by macrophages.

The results were normalized to $1 \mathrm{mg}$ LDL protein per $\mathrm{ml}$ of solution. A. LDL was oxidized by radiation and the hydroperoxides assayed by two methods before and after anaerobic decomposition with $\mathrm{Cu}^{2+}$. Line $\mathrm{A}$, iodide assay, no copper; line B, TBARS, no copper; line C, TBARS, $20 \mu \mathrm{M}$ copper; line D, iodide assay, $20 \mu \mathrm{M}$ copper. B. The uptake of total and esterified cholesterol by macrophages from ox-LDL. Line E, total cholesterol from ox-Cu-LDL; line F, total cholesterol from ox-LDL; line G, free cholesterol from ox-Cu-LDL; line H, free cholesterol from ox-LDL.

ately on irradiation, it required radiation doses of 700-1000 Gy to convert it to a form causing cholesterol accumulation in macrophages (Fig. 2B). These doses generated 300-400 nmol hydroperoxide and 15-17 nmol TBARS per mg of LDL protein. Large radiation doses, in excess of $1000 \mathrm{~Gy}$, were able to cause the LDL to be taken up by macrophages at increasing rates even in the absence of copper. However, for any given hydroperoxide concentration, the uptake of both free and esterified cholesterol was greatly enhanced by treatment with the metal (Fig. 2B). The incubation of ox-LDL with $\mathrm{Cu}^{2+}$ produced ultimately a fourfold increase in cholesterol accumulation.

An attempt was made to establish the minimum amount of hydroperoxide whose decomposition converted the LDL into the form avidly taken up by the macrophages. Results obtained with LDL samples from three different subjects are shown in Fig. 3. The amounts of decomposed peroxides were estimated from the difference between peroxide levels before and after incubation with copper. Each sam- ple showed an initial period in which there was no enhanced macrophage uptake, fol-

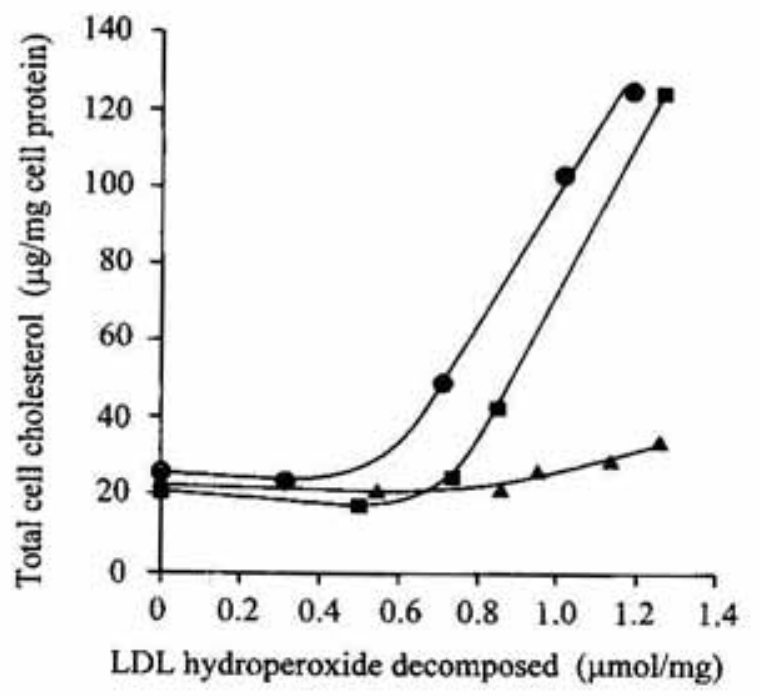

Figure 3. The effect of sample origin on LDL cholesterol accumulation.

Mouse macrophages were incubated with modified LDL isolated from 3 different subjects. The LDL was oxidized by radiation and $80-100 \%$ of the hydroperoxides decomposed by treatment with $\mathrm{Cu}^{2+}$ in the absence of oxygen. 
lowed by a rapid increase at when higher amounts of copper-decomposed hydroperoxides were present. The results also show a large variability between the samples in the length of the lag and in the amount of LDL cholesterol accumulated by the cells exposed to a given amount of decomposed hydroperoxides. For these and other samples studied, no increase in LDL uptake was ever observed until the level of decomposed peroxides reached at least $0.3 \mu \mathrm{mol} / \mathrm{mg}$ of LDL protein. Study of the processing of the ox-LDL by macrophages showed that a considerable proportion of the ${ }^{125}$ T-labeled ox-LDL and ox-Cu-LDL taken up by the cells was present as undegraded, cellassociated lipoprotein (Fig. 4). In agreement with the results obtained from measurements of cell cholesterol accumulation (Fig. 2B), the ox-LDL was taken up by the cells at much higher rates after exposure to the $\mathrm{Cu}^{2+}$. In the $40 \mathrm{~h}$ incubation, some of the native LDL was degraded by the macrophages, but no accumulation could be detected. The process of ox$\mathrm{Cu}-\mathrm{LDL}$ uptake was apparently saturable.

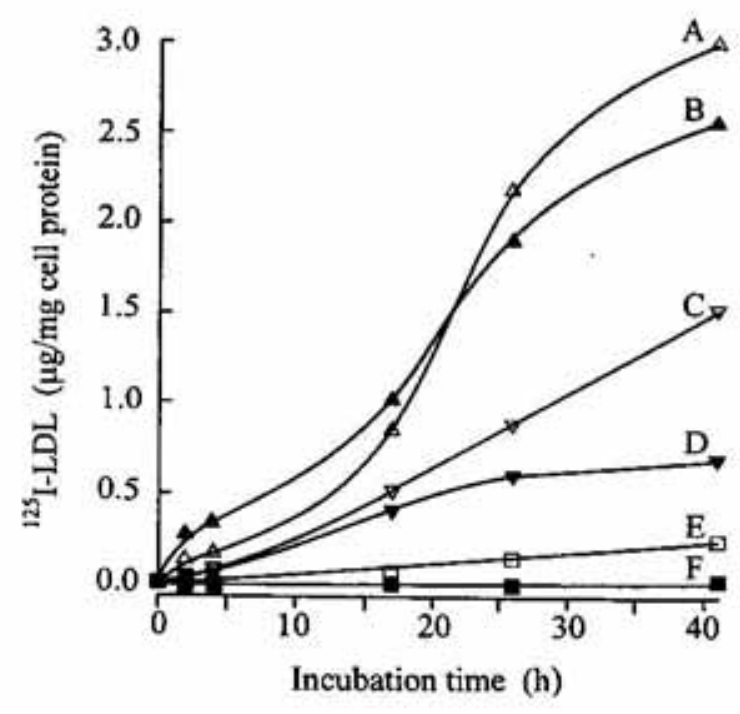

Figure 4. Processing of native, ox- and ox-Cu-LDL by macrophages.

The ox-LDL contained initially $0.63 \mu \mathrm{mol}$ hydroperoxide/mg LDL protein; this was decomposed by $20 \mu \mathrm{M}$ $\mathrm{Cu}^{2+}$ to form ox-Cu-LDL. Open symbols, degraded LDL; closed symbols, cell-associated LDL. Lines A and $\mathrm{B}$, ox-Cu-LDL; lines $\mathrm{C}$ and D, ox-LDL; lines $\mathrm{E}$ and F, native LDL.
We observed that the copper-induced anaerobic decomposition of LDL hydroperoxides was accompanied by aggregation of the particles. This was quantitated by measuring the absorbance of the lipoprotein solution at $680 \mathrm{~nm}$ (Fig. 5A). Although the $\mathrm{A}_{680}$ increased only slightly in the course of irradiation, subsequent incubation with $\mathrm{Cu}^{2+}$ produced significant increase of absorbance values for any radiation dose absorbed. This rise was closely reflected by increasing cholesterol accumulation in the macrophages (Fig. 5B).

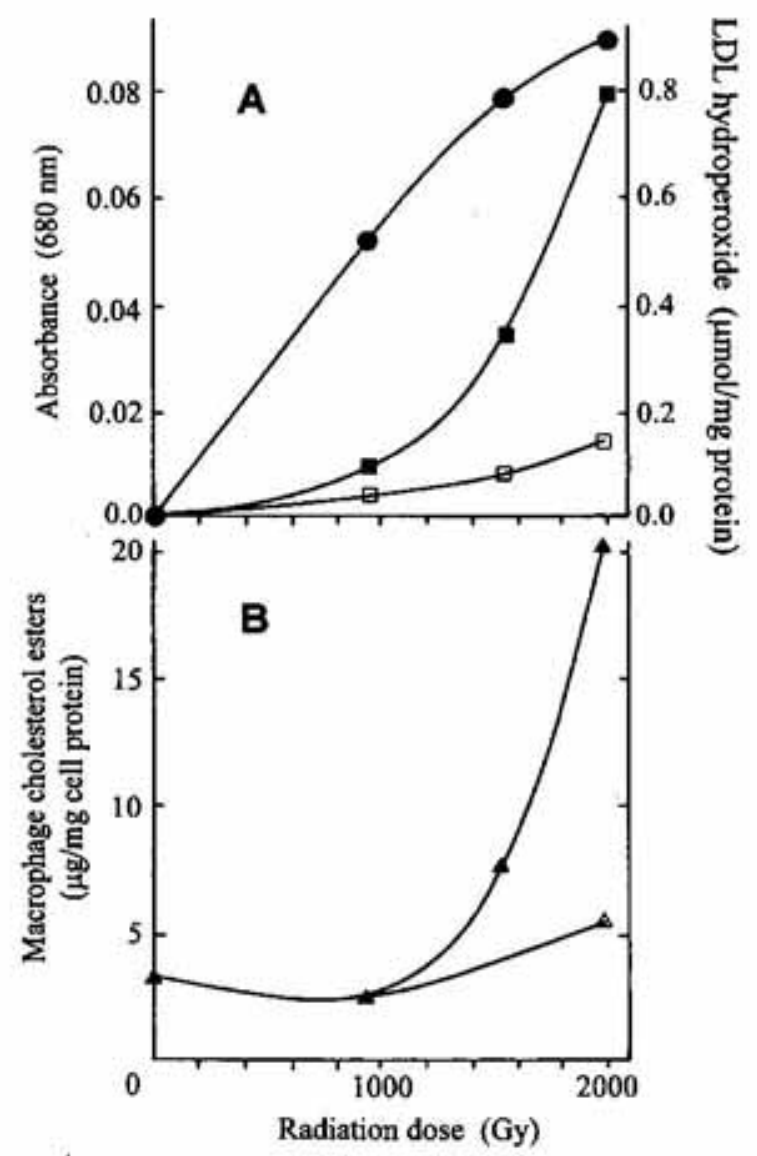

Figure 5. Correlation of the aggregation and uptake of oxidized LDL.

LDL was peroxidized to different levels by radiation and the ox-Cu-LDL derived from it by copper treatment. Particle aggregation was monitored at $680 \mathrm{~nm}$. Panel A: circles, absorbance readings; squares, hydroperoxide levels in ox-LDL (filled squares) and in ox-CuLDL (open squares). Panel B: cholesterol esters accumulated in macrophages incubated with ox-Cu-LDL (filled triangles) and ox-LDL (open triangles). 

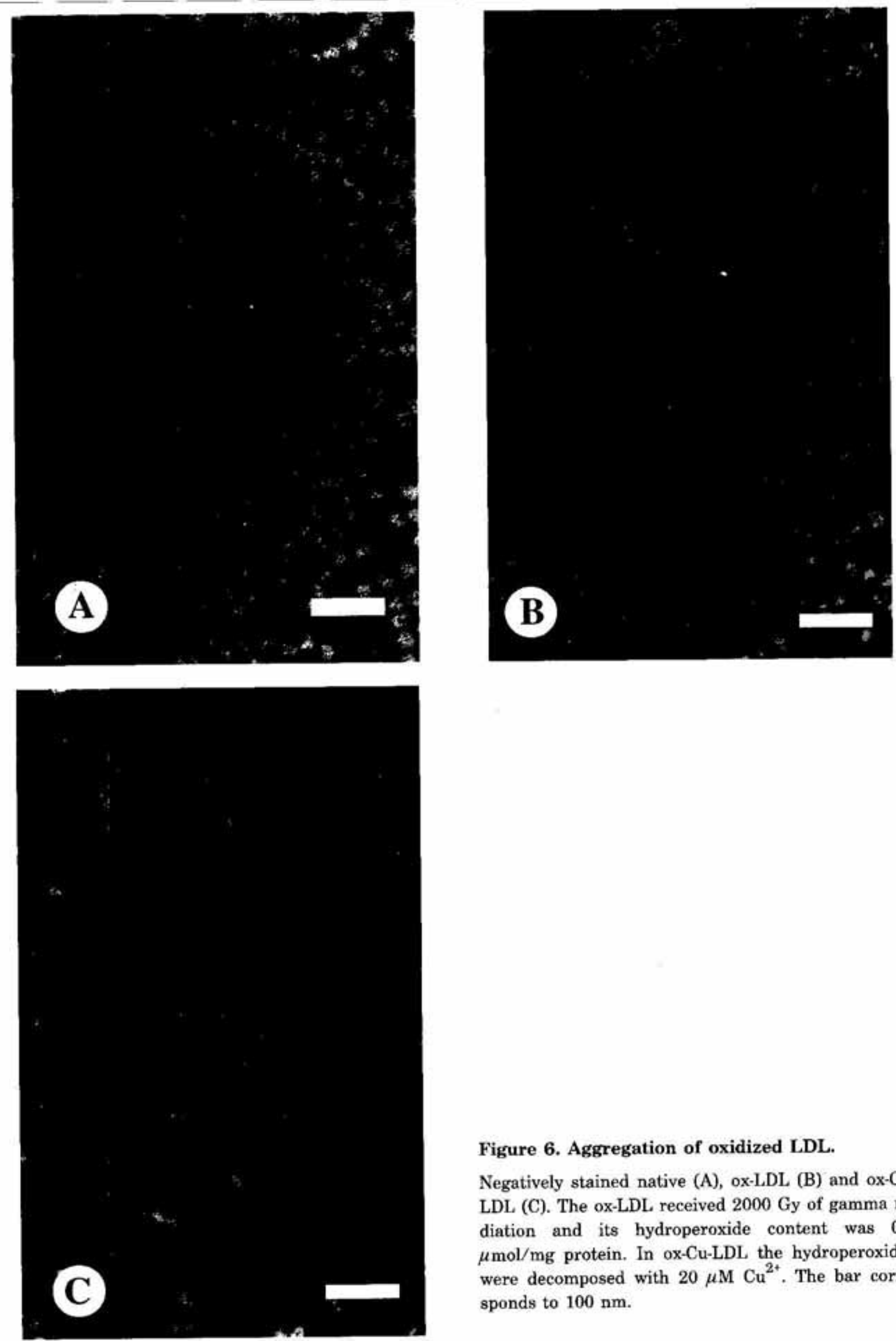

Figure 6. Aggregation of oxidized LDL.

Negatively stained native (A), ox-LDL (B) and ox-CuLDL (C). The ox-LDL received $2000 \mathrm{~Gy}$ of gamma radiation and its hydroperoxide content was 0.9 $\mu \mathrm{mol} / \mathrm{mg}$ protein. In ox-Cu-LDL the hydroperoxides were decomposed with $20 \mu \mathrm{M} \mathrm{Cu}{ }^{2+}$. The bar corresponds to $100 \mathrm{~nm}$. 
Table 1. The mode of uptake of oxidized LDL by macrophages.

The ox-LDL and ox-Cu-LDL $(20 \mu \mathrm{g} / \mathrm{ml})$ were added to the macrophages alone (control samples) or in the presence of $200 \mu \mathrm{g} / \mathrm{ml}$ native LDL (n-LDL), $200 \mu \mathrm{g} / \mathrm{ml}$ acetylated LDL, or $10 \mu \mathrm{g} / \mathrm{ml}$ of cytochalasin B. The oxLDL contained $0.8 \mu \mathrm{M}$ lipid hydroperoxide. The results are averages of two sets of measurements.

\begin{tabular}{lc}
\hline Sample & $\begin{array}{r}125 \\
\text { T-LDL degraded } \\
\text { (\% of control) }\end{array}$ \\
\hline ox-LDL + n-LDL & 54 \\
ox-Cu-LDL + n-LDL & 100 \\
ox-LDL + ac-LDL & 4 \\
ox-Cu-LDL + ac-LDL & 35 \\
ox-LDL + cytochalasin B & 45 \\
ox-Cu-LDL + cytochalasin B & 48 \\
\hline
\end{tabular}

Under the electron microscope, the negatively stained ox-Cu-LDL was seen as aggregates of relatively heterogeneously sized particles (Fig. 6). The proportion of aggregated material and size of the aggregates progressively increased with the dose of radiation and degree of oxidation of the LDL. The radiation oxidized LDL did not aggregate significantly if not exposed to $\mathrm{Cu}^{2+}$, although some forma- tion of particles larger than the native LDL could be observed.

To investigate the routes of uptake of ox$\mathrm{LDL}$ and ox-Cu-LDL, we measured the ability of native or acetylated LDL to inhibit their degradation by the macrophages (Table 1). Native LDL was unable to inhibit the degradation of ox-Cu-LDL, whereas a 10 -fold excess of acetylated LDL inhibited by $65 \%$. In the same set of experiments the role of phagocytosis in the uptake process was tested by the addition of cytochalasin B to the macrophage culture medium. This led to a $50 \%$ reduction of the ox$\mathrm{Cu}-\mathrm{LDL}$ uptake. The degradation of ox-LDL was inhibited by both the native and acetylated LDL and by cytochalasin B. Separate tests showed that the dimethylsulfoxide used as a solvent for cytochalasin B had no effect on the lipoprotein degradation.

The ability of $\mathrm{Cu}^{2+}$ to decompose LDL hydroperoxides with concomitant generation of its high uptake form suggested that iron could produce similar effect. The results (Table 2) demonstrate that free and chelated iron induced the decomposition of radiationperoxidized LDL with varying effectiveness. The extent of LDL modification, as shown by cholesterol accumulation in macrophages,

Table 2. Ox-LDL breakdown and conversion to the high uptake form by iron.

LDL oxidized by radiation was incubated with the reagents listed in absence of oxygen for $17 \mathrm{~h}$ at $37^{\circ} \mathrm{C}$. Results of uptake by macrophages are from triplicate experiments. The hydroperoxide and TBARS concentrations were normalized to $\mathrm{mg}$ LDL protein; cholesterol esters concentrations are given per $\mathrm{mg}$ of cell protein.

\begin{tabular}{lccc}
\hline LDL sample & Hydroperoxide & TBARS & Cholesterol esters taken up \\
\cline { 2 - 4 } & $(\mu \mathrm{mol} / \mathrm{mg})$ & $(\mathrm{nmol} / \mathrm{mg})$ & $(\mu \mathrm{g} / \mathrm{mg})$ \\
\hline Native $\mathrm{LDL}$ & 0.0 & 0.8 & $3.2 \pm 0.4$ \\
Ox-LDL & 0.704 & 15.0 & $2.3 \pm 0.7$ \\
Ox-LDL incubated with: & & & \\
$20 \mu \mathrm{M} \mathrm{FeSO}_{4}$ & 0.97 & 14.2 & $115.2 \pm 20.4$ \\
$\mathrm{FeSO}_{4}+80 \mu \mathrm{M}$ EDTA & 0.533 & 10.1 & $4.1 \pm 0.6$ \\
$\mathrm{FeSO}_{4}+80 \mu \mathrm{M}$ citrate & 0.266 & 14.4 & $13.8 \pm 1.8$ \\
$\mathrm{FeSO}_{4}+80 \mu \mathrm{M} \mathrm{ADP}$ & 0.192 & 13.0 & $63.1 \pm 3.9$ \\
$2 \mu \mathrm{M} \mathrm{FeSO}_{4}+10 \%$ LDS & 0.540 & 7.2 & $3.4 \pm 0.8$ \\
\hline
\end{tabular}


was even greater than that produced by $\mathrm{Cu}^{2+}$. Free $\mathrm{Fe}^{2+}$ was the most effective form of the metal. Lipoprotein deficient serum (LDS) or EDTA added to the incubation solution containing peroxidized LDL and $\mathrm{Fe}^{2+}$ inhibited LDL modification almost completely and greatly reduced the decomposition of the hydroperoxides.

\section{DISCUSSION}

The use of ionizing radiation to generate LDL lipid hydroperoxides and metals to decompose them has allowed us to study separately the role of each in the formation of atherogenic forms of LDL. This approach extended the work of Bedwell et al. [13] on the action of defined free radicals on LDL, which showed that formation of hydroperoxides is not sufficient to produce uncontrolled uptake of the lipoprotein by macrophages. Other studies have shown that irradiation of LDL in aqueous solutions leads to lipid oxidation which increases linearly with radiation dose, after an initial lag period imposed by the presence of antioxidants [13, 17]. No significant peroxide decomposition occurs during the irradiation, providing the system contains no transition metals able to react with organic hydroperoxides. Many studies have confirmed that the exposure of unoxidized LDL to $\mathrm{Cu}^{2+}$ is insufficient to change it to a form avidly taken up by macrophages [12]. Reactions between the hydroperoxide groups and the radiation-generated $\mathrm{HO}^{\circ}$ free radicals causing the lipid oxidation have very low probability because of the huge excess of other potentially reactive groups in the LDL particles. Experimental proof of this is provided by the linear relationship between radiation dose and the amount of oxidation [17]; any peroxide breakdown during irradiation would be detected as a gradual decrease in its rate of formation.

The standard TBARS assay detects principally one lipid peroxide decomposition prod- uct formed before or during the assay [21]. In absence of metal ions, the stability of the LDL hydroperoxides was shown by the 10-20 times lower levels of TBARS in samples peroxidized by radiation when compared with LDL oxidized to similar extent by $\mathrm{Cu}^{2+}$. The TBARS found in irradiated samples were probably formed by thermal decomposition of LDL lipid peroxides, mainly during the assay procedure. The ability of $\mathrm{Cu}^{2+}$ to decompose LDL hydroperoxides (Fig. 1) agrees with other reports demonstrating rapid breakdown of organic peroxides in the presence of cupric ions [22]. However, even a relatively brief incubation of the peroxidized LDL with no added $\mathrm{Cu}^{2+}$ at $37^{\circ}$ produced significant hydroperoxide breakdown. In these incubations no confusion could arise from simultaneous generation of new hydroperoxides, because oxygen was excluded. Both ox-LDL and ox-CuLDL induced cholesterol accumulation in macrophages, although the former was much less effective. This result can be reconciled with the report that LDL oxidized by radiation in the absence of $\mathrm{Cu}^{2+}$ is not taken up by macrophages at higher rate than native LDL [13] by the much larger (approx. 10-fold) amounts of LDL peroxides initially present in our irradiated samples. It is unlikely that the radiation doses employed in this study directly modified the apo $B$ protein, causing the LDL to be converted to the high-uptake form. Although the protein is located largely at the particle surface, it constitutes only $20 \%$ of its mass. The hydroxyl free radicals responsible for the peroxide formation [13] attack the LDL randomly, with little chance of inducing the highly specific changes to the apo $\mathrm{B}$ amino acids required for recognition by the macrophage scavenger receptors [12].

Experiments with LDL isolated from several subjects demonstrated that the degree of modification of the ox-Cu-LDL depended not only on the radiation dose and peroxide concentration, but also varied significantly between individuals. Thus, in vivo the formation of atherogenic LDL may not depend solely on 
the extent of decomposition of its hydroperoxides. Presumably the crucial step is modification of the apo $B$ amino acids by aldehydes released in peroxide breakdown [8]. This is likely to depend on the initial composition of the LDL lipids, effectiveness of the antioxidants present, the spectrum of aldehydes produced, and structural features of the particles which may facilitate or inhibit reactions between the aldehydes and amino acids. Aggregation of the oxidized LDL may play an important role in these events (Fig. 5). Whichever of these variables will be ultimately shown to play a decisive role, the results shown in Fig. 3 suggest that at least 150 hydroperoxide groups per LDL particle had to be formed in order to render it recognizable to the scavenger receptors of the macrophages.

The oxidized LDL, whether treated with $\mathrm{Cu}^{2+}$ or not, stimulated mainly the accumulation of esterified rather than free cholesterol (Fig. 2B). Copper-oxidized LDL is more resistant to intracellular degradation by macrophages than acetylated LDL [23]. Our data on the kinetics of ${ }^{125} \mathrm{I}-\mathrm{ox}-\mathrm{LDL}$ and ${ }^{125} \mathrm{I}-\mathrm{ox}-\mathrm{Cu}$ LDL uptake by the cells demonstrated that these modified lipoproteins are metabolized similarly, with a large proportion of the internalised ${ }^{125}$ I-labeled LDL accumulating without further degradation (Fig. 4). Oxidation of LDL by irradiation and subsequent treatment with $\mathrm{Cu}^{2+}$ converted the lipoprotein into the more negatively charged form (data not shown). This is a common observation with LDL oxidized in presence of metal ions and is due to the loss of charges on lysine residues reacting with aldehydes released by lipid hydroperoxide breakdown [24]. Aggregation has also been reported for radiation-oxidized LDL [13]. Formation of most of these aldehydes does not require the presence of oxygen [25]. Aggregation of the ox-Cu-LDL particles can be due to several causes. Free radicals generated during decomposition of lipid peroxides can damage proteins [26]. The anaerobic conditions employed here would favor crosslinking rather than scission of the polypeptide chains [27], generating inter- and intraparticle bonds. Direct damage to the protein component of the LDL during irradiation can lead to denaturation and exposure of hydrophobic residues on the protein surface, further facilitating aggregation [28]. The ox-LDL was taken up by macrophages via both the LDL and the scavenger receptors, whereas the ox$\mathrm{Cu}$-LDL uptake involved only the latter (Table 1). Phagocytosis also played an important role in the metabolism of both forms of the modified lipoproteins. For ox-Cu-LDL this was consistent with its aggregation. The involvement of the native LDL receptor in oxLDL uptake can be explained by the comparatively low degree of modification induced in the early stages of the LDL oxidation. It is interesting to note that macrophages incubated with minimally peroxidized LDL or ox-CuLDL consistently contained slightly less cholesterol than cells incubated with native the LDL (Figs. 2, 5). A similar effect was reported previously [13]. It seems likely that low levels of oxidation produced a heterogeneous population of particles, some largely unaltered, and others modified to some extent. The modified population might no longer be recognized by the LDL receptor, so that the macrophages would take up overall a smaller amount of cholesterol. Further oxidation would produce more extensive LDL modification with a population of particles increasingly recognized by the macrophage scavenger receptors. Iron $\left(\mathrm{Fe}^{2+}\right.$ and $\left.\mathrm{Fe}^{3+}\right)$ was more efficient than $\mathrm{Cu}^{2+}$ in modifying the ox-LDL, but not in decomposing the LDL hydroperoxides (Table 2). Differences in the localization and number of binding sites for $\mathrm{Cu}^{2+}$ and iron could explain these observations. The high efficiency of hydroperoxide decomposition shown by $\mathrm{Cu}^{2+}$ (Figs. 1 and $2 \mathrm{~A}$ ) indicates that the reactive groups generated by the irradiation are located at sites readily accessible to the metal, near the surface of the particles. This is not surprising, because the hydroxyl radicals responsible for the oxidation are too 
reactive to penetrate below the LDL surface. The inhibition of the hydroperoxide decomposition and ox-LDL modification by EDTA and LDS (Table 2) is consistent with the known ability of these agents to prevent LDL modification [12].

Taken overall, our results confirm that several variables determine the rate of uptake of oxidized LDL by macrophages. One is the degree of oxidation of the particles, and another the extent of hydroperoxide decomposition. LDL, oxidized to the small extent of 150 hydroperoxide groups or less on average, is not taken up by the cells any more readily than native LDL, regardless of the presence of $\mathrm{Cu}^{2+}$. In fact, the uptake is slightly reduced. Higher levels of oxidation lead to increased uptake which is dramatically enhanced by decomposition of the hydroperoxide. However, even in the absence of added metals, some peroxide decomposition occurs and the modified LDL is taken up. Extensively modified LDL populations are likely to contain a mixture of particles whose relative abundance depends on the history of the sample: unaltered LDL, LDL characterized by high anodic mobility, and particle aggregates. Thus, for more extensively modified LDL samples, the uptake of cholesterol by macrophages involves the LDL receptors as well as the scavenger receptors, and phagocytosis. These observations may be relevant to ischemic events in vivo, where oxygen may be largely absent, especially if chelated transition metals able to decompose lipid hydroperoxides are available.

We acknowledge gratefully the advice and practical help with labeling experiments given by Dr. Wendy Jessup.

\section{RE F E R E N C E S}

1. Goldstein, J.L., Ho, Y.K., Basu, S.K. \& Brown, M.S. (1979) Binding site on macrophages that mediates uptake and degradation of acety- lated low density lipoprotein, producing massive cholesterol deposition. Proc. Natl. Acad. Sci. U.S.A. 76, 333-337.

2. Fogelman, A.M., Shechter, I., Saeger, J., Hokom, M., Child, J.S. \& Edwards, P.A. (1980) Malondialdehyde alteration of low density lipoproteins leads to cholesterol ester accumulation in human monocyte-macrophages. Proc. Natl. Acad. Sci. U.S.A. 77, 2214-2218.

3. Hoff, H.F., O'Neil, J., Chisolm, G.M., Cole, T.B., Quehenberger, O., Esterbauer, H. \& Jurgens, G. (1989) Modification of low density lipoprotein with 4-hydroxynonenal induces uptake by macrophages. Arteriosclerosis $\mathbf{9}$, 538-549.

4. Henriksen, T., Mahoney, E.M. \& Steinberg, D. (1981) Enhanced macrophage degradation of low density lipoprotein previously incubated with cultured endothelial cells: recognition by receptor for acetylated low density lipoproteins. Proc. Natl. Acad. Sci. U.S.A. 78, 6499-6503.

5. Parthasarathy, S., Printz, D.J., Boyd, D., Joy, L. \& Steinberg, D. (1986) Macrophage oxidation of low density lipoprotein generates a modified form recognized by the scavenger receptor. Arteriosclerosis 6, 505-510.

6. Khoo, J.C., Miller, E., McLoughlin, P. \& Steinberg, D. (1988) Enhanced macrophage uptake of low density lipoprotein after self aggregation. Arteriosclerosis 8, 348-358.

7. Hoff, H.F., Whitaker, T.E. \& O'Neil, J. (1992) Oxidation of low density lipoprotein leads to particle aggregation and altered macrophage recognition. J. Biol. Chem. 267, 602-609.

8. Steinberg, D., Parthasarathy, S., Carew, T.E., Khoo, J.C., \& Witztum, J.L. (1989) Beyond cholesterol. Modifications of low-density lipoprotein that increase its atherogenicity. $N$. Engl. J. Med. 320, 915-924.

9. Esterbauer, H. \& Ramos, P. (1995) Chemistry and pathophysiology of oxidation of LDL. Rev. Physiol. Biochem. Pharmacol. 127, 31-64. 
10. Klatt, P. \& Esterbauer, H. (1996) Oxidative hypothesis of atherogenesis. J. Cardiovascular Risk 3, 346-351.

11. Hunt, J.V., Bailey, J.R., Schultz, D.L., McKay, A.G. \& Mitchinson, M.J. (1994) Apolipoprotein oxidation in the absence of lipid peroxidation enhances LDL uptake by macrophages. FEBS Lett. 349, 375-379.

12. Gebicki, J.M., Jurgens, G. \& Esterbauer, H. (1991) Oxidation of low-density lipoprotein in vitro; in Oxidative Stress: Oxidants and Antioxidants (Sies, H., ed.) pp. 371-397, Academic Press, London.

13. Bedwell, S., Dean, R.T. \& Jessup, W. (1989) The action of defined oxygen-centered free radicals on human low-density lipoprotein. Biochem. J. 262, 707-712.

14. Redgrave, T.G., Roberts, D.C.K. \& West, C.E. (1975) Separation of plasma lipoproteins by density gradient ultracentrifugation. Anal. Biochem. 65, 42-49.

15. Bilheimer, D.W., Eisenberg, S. \& Levy, R.I. (1972) The metabolism of very low density lipoprotein proteins. I. Preliminary in vitro and in vivo observations. Biochim. Biophys. Acta 260, 212-221.

16. Hicks, M. \& Gebicki, J.M. (1979) A spectrophotometric method for the determination of lipid hydroperoxides. Anal. Biochem. 99, 249-253.

17. Babiy, A.V., Gebicki, J.M. \& Sullivan, D.R. (1990) Vitamin E content and low density lipoprotein oxidizability induced by free radicals. Atherosclerosis 81, 175-182.

18. Gamble, W., Vaughan, M., Kruth, H.S. \& Avigan, J. (1978) Procedure for determination of free and total cholesterol in micro- or nanogram amounts suitable for studies with cultured cells. J. Lipid Res. 19, 1068-1070.

19. Lowry, O.H., Rosebrough, N.J., Farr, A.L. \& Randall, R.J. (1951) Protein measurement with the Folin reagent. J. Biol. Chem. 193, 265-275.
20. Forte, T.M. \& Nordhausen, R.W. (1986) Electron microscopy of negatively stained lipoproteins. Methods Enzymol. 128, 443-457.

21.Janero, D.R. \& Burghardt, B. (1989) Thiobarbituric acid-reactive malondialdehyde formation during superoxide-dependent, iron-catalyzed lipid oxidation: Influence of oxidation conditions. Lipids 24, 125-131.

22.0'Brien, P.J.O. (1969) Intracellular mechanisms for the decomposition of a lipid peroxide. I. Decomposition of a lipid peroxide by metal ions, heme compounds, and nucleophiles. Canad. J. Biochem. 47, 485-492.

23. Lougheed, M., Zhang, H. \& Steinbrecher, U.P. (1991) Oxidized low density lipoprotein is resistant to cathepsins and accumulates within macrophages. J. Biol. Chem. 22, 1451914525.

24. Esterbauer, H., Dieber-Totheneder, M., Waeg, G., Striegl, G. \& Jurgens, G. (1990) Biochemical, structural and functional properties of oxidized low-density lipoprotein. Chem. Res. Toxicol. 3, 77-92.

25. Esterbauer, H., Zollner, H. \& Schaur, R.J. (1990) Aldehydes formed by lipid oxidation: Mechanisms of formation, occurrence and determination; in Membrane Lipid Oxidation (Vigo-Pelfrey, C., ed.) pp. 239-268, CRC Press, Boca Raton.

26. Wolff, S.P. \& Dean, R.T. (1986) Fragmentation of proteins by free radicals and its effect on their susceptibility to enzymic hydrolysis. Biochem. J. 234, 399-403.

27. Hunt, J.V. \& Dean, R.T. (1989) Free radicalmediated degradation of proteins: The protective and deleterious effects of membranes. Biochem. Biophys. Res. Commun. 162, 10761084.

28. Davies, KJ.A., Lin, S.W. \& Pacifici, R.E. (1987) Protein damage and degradation by oxygen radicals. J. Biol. Chem. 262, 99149920. 